\title{
As potências médias e a democracia: um estudo de caso do Cazaquistão
}

\author{
Jéssica de Freitas Rabelo Amorim ${ }^{1}$; Lauralice Bezerra de Vasconcellos ${ }^{2}$; Mariana Lima \\ de Salles ${ }^{3}$; Tatiana Leite de Souza ${ }^{4}$
}

\begin{abstract}
Resumo
O conceito de "potência média" tem sido bastante discutido atualmente. Tendo em vista a projeção econômica do Cazaquistão no sistema internacional, por meio de políticas multivetoriais e cooperativas, questionaremos se é necessário que um país adote um regime democrático para ser considerado como potência média, partindo especialmente do pressuposto da Teoria da Interdependência Complexa que enfatiza que os fluxos econômicos e as capacidades de um país podem dar destaque a "pequenos" Estados no sistema internacional. Nesse sentido, acreditamos que o regime interno de um país não interfere na sua classificação como potência média, principalmente dentro de uma lógica econômica liberal.
\end{abstract}

\section{Palavras-chave}

Cazaquistão; Potência Média; Petróleo; Democracia; Interdependência Complexa.

\section{Abstract}

The concept of "middle power" country has been largely discussed these days. Considering the economical projection of Kazakhstan in the international system, through multidimensional and cooperative policies, we question if a country needs to adopt a democratic regime for it to be considered as a middle power country, basing especially on the assumptions of the Complex Interdependence theory, which emphasizes that economical fluxes and a country's capabilities can highlight "small" States in the international system. In that sense, we believe that a country's internal regime doesn't interfere on its classification as a middle power, especially inside a liberal logic.

\section{Keywords}

Kazakhstan; Middle Power; Oil; Democracy; Complex Interdependence.

\footnotetext{
${ }^{1}$ Jéssica de Freitas R. Amorim é aluna do curso de graduação em Relações Internacionais da PUC-MG.

${ }^{2}$ Lauralice B. de Vasconcellos é aluna do curso de graduação em Relações Internacionais da PUC-MG.

${ }^{3}$ Mariana Lima de Salles é aluna do curso de graduação em Relações Internacionais da PUC-MG.

${ }^{4}$ Tatiana Leite de Souza é aluna do curso de graduação em Relações Internacionais da PUC-MG.
} 


\section{Introdução}

Atualmente, há um intenso debate no campo das Relações Internacionais no que diz respeito ao conceito de "potência média" e a real importância de tais Estados no sistema internacional. Esse conceito será discutido questionando a relevância da presença de um regime democrático para que tal posição seja alcançada, e analisando até que ponto a condição econômica de um país se sobrepõe à sua situação política.

O presente artigo questionará os atuais conceitos a partir de um estudo de caso do Cazaquistão, analisando a sua posição no sistema internacional, a situação econômica do país, que teve um avanço expressivo - considerando o papel que o petróleo teve para essa ascensão - e a persistente ausência de um regime democrático neste processo. A situação do Cazaquistão será analisada sob a perspectiva teórica da Interdependência Complexa, de Robert Keohane e Joseph Nye (2000), que retrata de forma clara a grande importância que os fluxos, principalmente os econômicos, têm nas relações de um país, e para que um Estado se destaque e tenha influência sobre o sistema internacional.

\section{Afinal, o que é uma potência média?}

O intenso debate em torno do conceito de potência média parece ter alcançado certo consenso em torno da colocação abaixo:

Todas potências médias apresentam uma política externa que estabelece e legitima a ordem global, tipicamente por meio de iniciativas multilaterais e cooperativas. [...] [As] potências médias tradicionais são saudáveis, estáveis, igualitárias, socialdemocráticas e não influenciadas regionalmente. (BALCER, 2012).

Adam Balcer (2012) também coloca a democracia como fator importante para classificar uma nação como potência média, uma vez que, por estarem perto de serem influenciadores cada vez mais importantes no sistema, sua alteração para um regime democrático e a sua própria modernização serão condicionais para que consigam exercer tal influência.

Entretanto, ao analisar a realidade do Cazaquistão, questiona-se se a democracia realmente tem um papel fundamental para a colocação de um país em destaque no sistema internacional, uma vez que o desenvolvimento interno é um fator verdadeiramente importante para a sua projeção internacional, mas que não depende, necessariamente, da adoção de um regime democrático. 
Desde sua independência em 1991, o Cazaquistão tem apresentado um crescimento econômico expressivo devido, principalmente, ao comércio do seu petróleo. O fato de seu governo receber sérias acusações quanto a censuras à imprensa e à oposição ${ }^{5}$ não foi um empecilho para tal ascensão. Assim, ao desvencilhar o elemento da democracia do conceito atual, é possível chegar a uma nova categorização sobre potências médias.

\section{O Cazaquistão como um país independente}

Em 1991, com a dissolução da URSS (União das Repúblicas Socialistas Soviéticas) a Ásia Central se viu reformada, com a emergência de países como o Cazaquistão $^{6}$, Uzbequistão, Turcomenistão e Tadjiquistão, que transformaram a Ásia Central em uma região nova e independente (USAID, 2012).

Após viver quase um século sob os preceitos do comunismo, e com um amplo setor agrícola, dedicado principalmente ao abastecimento da própria URSS (IDEM, 2012), os Estados recém-formados precisavam lidar com o capitalismo e a economia de mercado. Despreparados, estavam fadados a dependerem economicamente das potências da região - especialmente da Rússia - até que fossem capazes de diversificar suas produções e poderem competir nessa nova realidade.

Porém, a abundante existência de petróleo, descoberto ainda em $1899^{7}$, foi suficiente para mudar a previsão: para garantir o poder de influência sobre a região, a Rússia - à qual o Cazaquistão estava unido desde 1730, na época do Império Russo (IDEM, 2012) - precisaria competir com países como os Estados Unidos, a China e inclusive alguns países europeus, interessados no "ouro negro" da região da Ásia central (VISENTINI, 2012). Com isso, foi criada uma nova configuração na região da Ásia Central, que:

\footnotetext{
5 "Nursultan Nazarbayev tornou-se o presidente vitalício" - Correio do Brasil, 15 maio de 2011. Disponível em: <http://correiodobrasil.com.br/nurusltan-nazarbayev-tornou-se-opresidentevitalicio/240085/\#.UJxBzOTAcqM>. Acesso em: 10 out. 2012.

6 "Not-quite-eternal Nursultan. A success story, but the ending is not yet written - The Economist Newspaper Limited, 17 de dezembro de 2011. Disponível em: $\langle$ http://www.economist.com/node/21541853?zid=309\&ah=80dcf288b8561b012f603b9fd9577f0e >. Acesso em: 10 set. 2012.

7 A respeito disso, ver "History of Kazakhstan Oil Industry". Disponível em: 〈http://englishrussia.com/2011/09/26/history-of-kazakhstan-oil-industry/〉. Acesso em: 17 out. 2012.
} 
[...] teve tanto implicações econômicas como de segurança, levando os maiores Estados da região a articular um lócus de cooperação nestas duas áreas. As razões para o estabelecimentos desses novos mecanismos de cooperação eram, inicialmente, voltados apenas para a busca de estabilidade regional. Mas com a projeção dos interesses norte-americanos para este novo e desorganizado espaço, a cooperação sino-russo-centro-asiática buscou criar um contrapeso a tal influência. Num primeiro momento, o Uzbequistão, país mais populoso e com as melhores forças armadas, tomou a dianteira, mas, nos últimos anos, o Cazaquistão, detentor de um território maior e de economia mais avançada, sobrepujou seu vizinho, e hoje, sob os pontos de vista econômico e estratégico, é o terceiro país mais importante da OCX. (VISENTINI, 2012, p.235).

O Cazaquistão se mostrou, ao longo da última década, um exemplo quanto à busca pela garantia de que seus interesses fossem sempre sobrepostos aos interesses estrangeiros (BHADRAKUMAR, 2009). A presença de petróleo fez com que o país se destacasse no sistema internacional e atraísse investidores diversos (ERNST \& YOUNG, 2011), como mostra a expansão surpreendente de seus índices econômicos na década de 2000 (INDEX MUNDI, 2011).

\section{Uma análise sob o enfoque teórico da Interdependência Complexa}

Para entender como países com pouca expressão no Sistema Internacional passaram a exercer um papel importante no cenário mundial, a teoria da interdependência complexa (KEOHANE \& NYE, 2000) oferece uma forma diferente de mensurar o poder dos Estados. Os motivos pelos quais esses países "emergentes" assumem uma nova posição no cenário, a ponto de se tornarem capazes de ameaçar o status das maiores potências do mundo são a globalização econômica e a importância que suas economias passam a exercer nesse processo, ao passo que a força militar perde seu papel de critério para a mensuração de poder (NYE JR., 2002).

Desta forma, ao analisar a situação do Cazaquistão, destaca-se a importância que o petróleo teve para alavancar o desenvolvimento econômico do país e para servir de uma importante fonte de interesses de investidores internacionais (ERNST \& YOUNG, 2011), fazendo com que o país ganhasse destaque na região centro-asiática ao longo dos anos.

Foi durante a década de 1970 que a forma como os atores internacionais se relacionavam foi percebida como fortemente caracterizada por uma complexa rede de conexões mútuas - e, ainda assim, assimétricas - formadas principalmente por fluxos econômicos. Ao serem assimétricas, significa que um ator tem maior grau de dependência 
em relação ao outro (NYE JR., 2002,) e, assim, os atores não têm o mesmo peso nas decisões. Por outro lado, o poder econômico se divide em diversas temáticas, e um país pode ser protagonista em uma determinada área, mas ser um mero figurante em outra.

Com a Crise do Petróleo de 1973, a questão da assimetria nas relações entre os países ficou mais evidente. Além de organizarem uma redução na extração petrolífera, os países detentores da maior parte do comércio mundial - em especial, os países membros da Organização dos Países Exportadores de Petróleo (OPEP) - decidiram aumentar o preço do barril (YERGIN, 1994). Esse acordo fez com que esses países se afirmassem como controladores da economia global, já que o petróleo era o motor do comércio e da indústria mundial (NYE JR, 2002). O episódio mostrou o poder que esses pequenos e até irrelevantes países poderiam exercer sobre os outros, sobretudo no que se diz respeito ao poder de barganha política (YERGIN, 1994).

Ainda que o clima de tensão prevalecesse durante esse período, o uso da força não se estabeleceu, pois:

De um modo geral, como as companhias petrolíferas são maximizadoras do lucro a longo prazo, [elas] procuraram estabilizar o mercado em vez de deixarem que a crise atacasse qualquer país de forma intensa. Ao reduzirem a ameaça de estrangulamento, reduziram a probabilidade da necessidade do uso da força. (NYE JR., 2002, p. 243.)

Desse modo, fica clara a maneira em que o petróleo passa a ser usado como um instrumento essencial para evitar que os países recorram à força para defenderem seus interesses e, de algum modo, para fazer com que um país seja projetado no sistema internacional e adquira relativa importância nele.

O grande problema da interdependência para os estados envolvidos no acordo dos produtores petrolíferos, é que os efeitos dessas relações dependem de constrangimentos e custos decorrentes destas. Em curto prazo, os Estados estão sujeitos à sensibilidade de reação aos custos e constrangimentos, enquanto que, no longo prazo, a vulnerabilidade dos mesmos é colocada à prova quando é necessário levar em consideração o custo para alterar o sistema em que se está inserido (NYE JR., 2002).

No caso do Cazaquistão, por exemplo, ser dependente da exportação de petróleo o colocaria em uma situação de extrema vulnerabilidade, não só por conta dos custos para mudar essa situação econômica, mas porque ele não teria recursos capazes de substituir esse modelo e provir a mudança. Por outro lado, mesmo que o Cazaquistão dependa de 
investimentos estrangeiros para garantir a continuação de seu desenvolvimento e a diversificação de sua economia, outros países também precisam e dependem do seu petróleo. Essa situação é propícia para que pactos comerciais sejam realizados a fim de diminuir as assimetrias entre os Estados, e para conquistar o bem-estar de todos os envolvidos, que é o objetivo final dessas relações - isto é, a consideração dos ganhos relativos (o que é melhor para cada um) em lugar dos ganhos absolutos (que se preocupam apenas com o aspecto quantitativo dos ganhos).

\section{A dinâmica interna e externa do Cazaquistão.}

Apesar das fortes investidas de empresas europeias e americanas nos anos 90 (KRAMER, 2007.) e da formação, em 1996, da organização "Os Cinco de Xangai" grupo formado por China, Rússia, Cazaquistão, Tadjiquistão e Quirguistão que, em 2001, se transformou na "Organização para a Cooperação de Xangai (OCX)", com a adesão do Uzbequistão ao grupo (VISENTINI, 2012) - o Cazaquistão e os países da Ásia Central passaram a ficar cada vez mais atentos à proteção de seus tesouros e à formação de uma política voltada para a satisfação socioeconômica de seus residentes, de modo a garantir a sua posição nas relações com os demais atores e não sofrer com as possíveis assimetrias destas. O Cazaquistão consegue manter-se em uma posição relativamente importante na região por ser o quarto maior exportador de petróleo e que não pertence à OPEP (Organização dos Países Exportadores de Petróleo) (BES, 2012.).

Ainda que o governo de Nursultan Nazarbayev seja conhecido pelas características ditatoriais - como a censura à imprensa, a perseguição a membros da oposição, e a sua recente promoção a "presidente vitalício" do país ${ }^{8}$ - ele se mostra interessado com o desenvolvimento socioeconômico do país, que, de fato, melhorou nos últimos anos: em 1999, a sua taxa de alfabetização era de 99,5\%; já em 2009, apresentou um gasto de 4,3\% do PIB em saúde ${ }^{9}$ (CIA, 2012); e, em 2011, sua taxa de desemprego era inferior a $6 \%$.

\footnotetext{
8 "Nursultan Nazarbayev tornou-se o presidente vitalício" - Correio do Brasil, 15 maio de 2011. Disponível em: <http://correiodobrasil.com.br/nurusltan-nazarbayev-tornou-se-opresidentevitalicio/240085/\#.UJxBzOTAcqM>. Acesso em: 10 out. 2012.

${ }^{9}$ A França, em comparação, gastou apenas 3,5\%.
} 
Os índices econômicos desses anos de governo surpreenderam o mundo, com crescimentos reais anuais que chegaram a ficar acima dos 7\% em 2010 e em 2011 (CIA, 2012.). Tal desenvolvimento só foi possível graças aos altos rendimentos provindos da exportação petrolífera, visto que mais de $20 \%$ de seu PIB é proveniente da exportação de recursos minerais (BES, 2012). Ainda, em março de 2002, o Departamento de Comércio dos EUA concedeu status de economia de mercado a Cazaquistão sob a legislação dos EUA (COUNTRY-FACTS, 2012).

Portanto, para garantir que esse desenvolvimento continue, é indispensável a proteção dos seus recursos naturais, em especial, do petróleo.

Nursultan Nazarbayev gosta de desenhar mapas na areia. O presidente do Cazaquistão comunicou recentemente às majors globais do petróleo e de minerais estratégicos que a nova legislação só admitirá, nos programas de investimento para explorar os recursos minerais do país, investidores estrangeiros que se disponham a cooperar para seu programa de industrialização. 'Só trabalharemos com os que nos apresentem projetos que contribuam para diversificar a economia', disse ele, dia 4/12, em conferência em Astana, capital do Cazaquistão [...]. Para estimular os que resistissem, acrescentou: "Procuramos novos parceiros e ofereceremos condições favoráveis e recursos para implantar os projetos". (BHADRAKUMAR, 2009.)

Atento ao interesse estrangeiro em seu país, o presidente Nazarbayev procurou manter uma política externa multivetorial, interagindo ao mesmo tempo com China, Rússia e Estados Unidos, de forma que suas relações exteriores, principalmente as negociações envolvendo o petróleo, tragam benefícios para o país ${ }^{10}$.

Os investimentos em petróleo feitos pelo Cazaquistão não cessam, principalmente depois da descoberta da jazida de Kashagan. Apesar das extrações iniciais serem esperadas apenas para o final de 2013, estima-se que a capacidade será de 9 a 16 bilhões de barris por dia. Em 2011, o PIB do país se concentrava em recursos minerais e na indústria extrativista (20,7\% do total), com apenas 11,8\% em produção industrial (BES, 2012). O Cazaquistão é, então, um país ainda muito dependente de suas riquezas naturais e dos investimentos que se originam dessas.

10 A respeito disso, ver: “A Importância Estratégica do Cazaquistão". Disponível em: $\langle$ http://www.cprepmauss.com.br/documentos/aimportanciaestrategicadocazaquistao85211.pdf>. Acesso em 15 out. 2012. 


\section{Gráfico 1- Produto Interno Bruto (PIB) - Taxa de Crescimento Real (\%)}

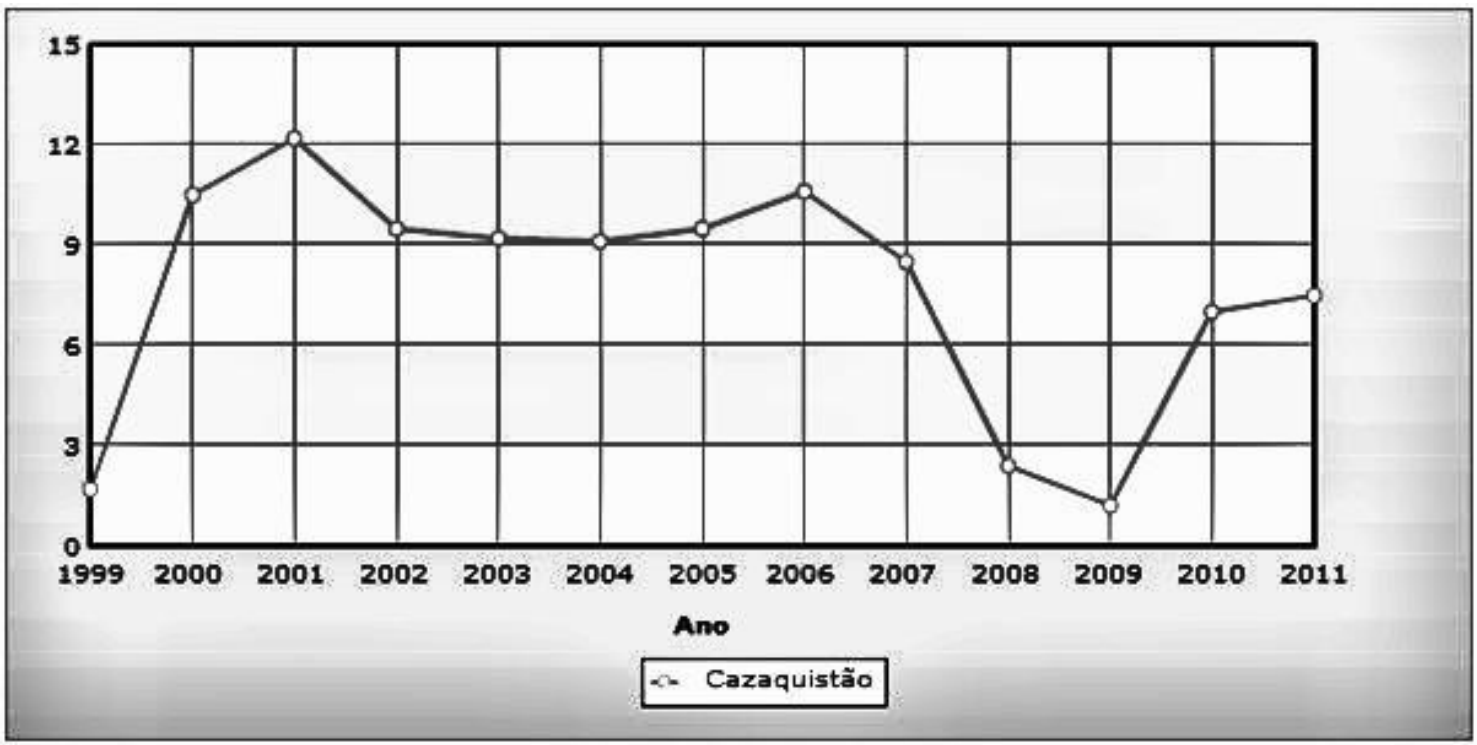

Fonte: INDEX MUNDI, 2011.

A crise econômica que abalou o mundo e que teve seu ápice em 2008 exaltou a dependência do Cazaquistão com relação às suas exportações petrolíferas, provocando uma redução dramática na taxa de crescimento de seu PIB, composto principalmente pelas exportações de recursos minerais para os países atingidos - principalmente para os Estados Unidos - cujos efeitos ainda são perceptíveis. A diversificação da economia se mostrou necessária para que o país se tornasse menos sensível aos abalos da balança comercial e, principalmente, aos efeitos gerados por uma possível crise nos principais países que importam seu petróleo (INDEX MUNDI, 2011).

Em 2010, o Plano de Desenvolvimento 2020 foi implantado visando deslocar sua economia da extração e exportação de matérias-primas e garantir aumento na produtividade (BES, 2012). Ainda em 2012, estabeleceu-se um programa industrial que objetivava produzir mais bens de alto valor agregado voltados para a exportação como uma forma aproximação aos mercados russo e bielorrusso ${ }^{11}$ (JSC, 2012). O setor agropecuário também não ficou atrás: o crescimento foi de 22,6\% entre 2006 e 2011 (BES, 2012).

${ }^{11}$ Este acordo, feito sob a forma de uma união aduaneira, a "EurAsEC", abre mais oportunidades aos investidores estrangeiros de implantarem projetos no Cazaquistão (JSC, 2012.) 
Assim, é possível notar que:

A crise financeira global acentuou a dependência da sua economia ao setor do petróleo que, aliado à redução de entrada de capitais, expôs o país à falta de liquidez e consequentemente à dificuldade no acesso ao financiamento externo. Para colmatar esta situação, as autoridades injetaram, até finais de 2010, mais de USD 20 mil milhões, com objetivo de apoiar sectores da construção, da agroindústria, dos serviços financeiros e as PME. (BES, 2012).

Apesar da Crise de 2008 ter exaltado a dependência do Cazaquistão e ter influenciado no seu crescimento econômico, o país conseguiu rapidamente desvencilharse de maiores riscos, o que não se verifica, por exemplo, com alguns países europeus, como a Espanha (MAZZI, 2012). Isso mostra que o Cazaquistão apresenta uma estabilidade interna capaz de suportar abalos da crise. Graças a essa nova política desenvolvida por Nazarbayev, o país tende a crescer mais, diminuindo consideravelmente sua vulnerabilidade com relação ao petróleo.

\section{Considerações finais}

Tendo em vista as considerações a respeito do Cazaquistão e sua projeção no sistema internacional por meio de políticas cooperativas e multivetoriais, é possível classificá-lo como uma potência média, ainda que não se trate de uma democracia. Considerando o conceito apresentado por Jordaan (2003), o país preenche todas as características necessárias para ser considerado como potência média, exceto do regime democrático. Sendo assim, é notável que a democracia não fora um requisito necessário para sua estabilidade econômica e seu grande desenvolvimento social.

Por outro lado, tem autores que não consideram a questão política de um país como fator caracterizador de uma potência média, adotando uma perspectiva mais liberal e focada na economia. Um deles é Denis Stairs (2008), cuja definição aborda um Estado que possui capabilities (capacidades ou recursos) que poderão ser usadas para projetar determinado país no sistema internacional.

Ainda que esteja em gradual processo de diversificação econômica, o Cazaquistão pode ser considerado como uma potência média, pois apresenta uma capability (petróleo) que vem sendo utilizada pelo país para ampliar ainda mais seu desenvolvimento econômico e se projetar no sistema internacional. Nos últimos anos, o petróleo vem sendo utilizado como uma ferramenta de barganha política entre aqueles países com os 
quais o Cazaquistão se relaciona, e também como um meio de aproximar os países da Ásia Central, que cooperaram para sobrepujarem a influência das grandes potências mundiais. Apesar de ainda ser dependente dos recursos provenientes do comércio de petróleo, “(...) o contínuo aumento da capacidade de produção petrolífera do Cazaquistão tem permitido a Astana [capital do país] diminuir a sua dependência face ao seu grande vizinho do norte." ${ }^{\prime 2}$ - isto é, a Rússia.

[Em 2005] foi também alterada legislação relativa ao subsolo que impede a posse de bens energéticos (energy assets) por empresas estrangeiras e legitima o governo a comprar de volta esses mesmos bens ${ }^{13}$.

O governo de Nursultan Nazarbayev também foi responsável por colocar os interesses do país e seu crescimento como prioridade. Os recursos provenientes do comércio de petróleo e de outros combustíveis fósseis foram os principais responsáveis por financiar essa expansão. Por isso, sua economia lhe trouxe uma posição vantajosa em relação aos seus vizinhos, o que além de lhe colocar como o protagonista da região, também tornou suas relações com estes assimétricas - sendo Cazaquistão um dos mais beneficiados nessa dinâmica.

De fato, o Cazaquistão é um bom aliado dos EUA na Ásia Central, sendo os EUA o principal investidor externo no país, e tendo o Cazaquistão enviado forças (não combatentes) para o Iraque e o Afeganistão. O próprio Secretário de Estado americano da Energia durante os últimos anos da Administração Clinton Bill Richardson afirmou peremptoriamente 'we're trying to move these newly independent countries towards the West' ${ }^{14}$.

Ao longo dos últimos anos, o fato de sua economia ter apresentado um expressivo crescimento em índices como o PIB, faz com que o país ganhe muita visibilidade no cenário regional e internacional, o que acaba por colocá-lo na posição de uma potência média, de acordo com Stairs. Mesmo que não se comporte externamente como um apaziguador de conflitos internacionais (ROYDS, 2000), o país exerce uma política de boa vizinhança com o mundo, e faz seus recursos gerarem benefícios internos (STAIRS, 2008), principalmente através de fluxos estatais e negociações de empresas.

\footnotetext{
12 "A Importância Estratégica do Cazaquistão". Disponível em: $\langle$ http://www.cprepmauss.com.br/documentos/aimportanciaestrategicadocazaquistao85211.pdf〉. Acesso em 15 out. 2012.

${ }^{13}$ C.f. nota 12 deste artigo.

${ }^{14}$ C.f. nota 12 deste artigo.
} 
Além dessas transações serem fundamentais nas relações descritas pela teoria da Interdependência Complexa, o fato do Cazaquistão se beneficiar dessas trocas acaba por mantê-lo afastado de um conflito.

A política externa do Cazaquistão, que temos vindo a analisar, tem sido oficialmente descrita como assentando numa estratégia diplomática multivetorial, através da qual Nazarbayev procura envolver simultaneamente as três maiores potências com influência sobre o seu país, Rússia, China e Estados Unidos garantindo assim a sua soberania através de uma hábil gestão de dependências e interdependências ${ }^{15}$.

Assim, o questionamento sobre o país precisar adotar um regime democrático para ser considerado como uma potência média ganha uma resposta diferente quando se analisa a situação do Cazaquistão. No próprio artigo de Adam Balcer (2012) não há consenso de que um país deva ser, necessariamente, uma democracia. Ele divide as potências médias em quatro grupos, sendo um deles formado por países autocráticos com um mercado livre. Estes países, além de manterem boas relações com os países ocidentais e de terem uma forte legitimidade interna, têm a sua política externa caracterizada por interações de soft e hard power. Na sua exemplificação, o autor analisa o caso da Arábia Saudita, apresentando-o como um país que consegue se promover regionalmente e ainda integrar seus vizinhos - o que também é possível perceber na análise das relações regionais do Cazaquistão.

Portanto, o regime político interno de um país não interfere, necessariamente, na sua classificação como potência média. Conforme discutido ao longo deste artigo, o Cazaquistão é um país autocrático que apresenta bom desenvolvimento socioeconômico e um bom grau de estabilidade interna (mais do que algumas grandes potências democráticas, como a Espanha, que vive entre movimentos étnicos e separatistas) ${ }^{16}$ graças ao uso do seu petróleo como fonte de desenvolvimento econômico. Sua projeção no sistema internacional é feita de forma positiva e lhe dá base para ser classificado como potência média.

\footnotetext{
${ }^{15}$ C.f. nota 12 deste artigo.

16 "Crise na Espanha faz renascer clamor separatista na Catalunha". Jornal do Brasil, 30 set. 2012. Disponível em: <http://www.jb.com.br/internacional/noticias/2012/09/30/crise-na-espanha-faz-renascerclamor-separatista-na-catalunhal>. Acesso em 23 fev. 2013.
} 


\section{Referências}

BALCER, Adam. Golden Age of Middle Powers? Warsaw: demos Europa: Centre for European Strategy Foundation, jan 2012. Trabalho elaborado no âmbito do projeto "Climate policy in the Polish Presidency of the Council of the European Union", Warsaw, 2012. Disponível em: < 〈http://www.demosservices.home.pl/www/files/AB_Policy_paper_Golden_age_of_Middle_Pow ers.pdf $>$. Acesso em 22 fev. 2013.

BES: Banco Espírito Santo. Cazaquistão: Síntese Econômica. Espírito Santo Research Research Sectorial. 2012, 27 p. Disponível em: $\langle$ http://www.bes.pt/sitebes/cms.aspx?plg=7d212776-a117-42fa-bed1-75aaefcc6551〉. Acesso em 31 out. 2012.

BHADRAKUMAR, M K. China resets terms of engagement in Central Asia. Asia Times, 24 dez. 2009. Disponível em: $\underline{w w w}$. atimes.com/atimes/Central_Asia/KL24Ag04.html >. Acesso em: 17 out. 2012.

C-PREP-MAUSS. A Importância Estratégica do Cazaquistão. Disponível em: $\langle$ http://www.cprepmauss.com.br/documentos/aimportanciaestrategicadocazaquista085211.pdf $>$. Acesso em 15 out. 2012.

CIA: Central Intelligence Agency. The World Factbook. Estados Unidos. Disponível em: 〈https://www.cia.gov/library/publications/the-world-factbook/geos/kz.html〉. Acesso em: 15 out. 2012.

CORREIO DO BRASIL. Nursultan Nazarbayev tornou-se o presidente vitalício. 15 maio 2011. Disponível em: $<$ http://correiodobrasil.com.br/nurusltan-nazarbayev-tornou-se-o-presidentevitalicio/ 240085/\#.UJxBzOTAcqM>. Acesso em: 10 out. 2012.

COUNTRY-FACTS. Cazaquistão - Parte 1 Economia. Disponível em: <http://countryfacts.com/pt/country/asia/179-kazakhstan/1461-kazakhstan-economy-part-1.html>.

Acesso em: 31 out. 2012.

ENGLISH-RUSSIA. History of Kazakhstan Oil Industry. Disponível em: $<$ http://englishrussia.com/2011/09/26/history-of-kazakhstan-oil-industry/>. Acesso em: 17 out. 2012.

ERNST \& YOUNG. Kazakhstan investment attractiveness. Kazakhstan: EYGM Limited 2011. $32 \quad$ p. $\quad$ Disponível em: 〈http://ipad.invest.gov.kz/upload/docs/501ff204a18f0766ba0b1833bbf6e673.pdf〉. Acesso em: 10 set. 2012.

FEDORENKO, Vladimir. Central Asia: From Ethnic to Civic Nationalism. Washington: Rethink Institute 2012. 23 p. Disponível em: 〈http://www.rethinkinstitute.org/files/Fedorenko\%20\%20Central\%20Asia\%20Nationalism.pdf >. Acesso em: 18 out. 2012. 
IDEM: Centro Científico do Instituto de Direito e Economia de Moscou. Império Russo - Parte 1(1613-1801). RUSSOBRAS - Projeto de Informação Sobre a Rússia. Disponível em: 〈http://www.russobras.com.br/historia/historia_3.php〉. Acesso em: 03 out. 2012.

IDEM: Centro Científico do Instituto de Direito e Economia de Moscou. A União das Repúblicas Socialistas Soviéticas (URSS) - Parte 1 (1917-1953). RUSSOBRAS projeto de informação sobre a Rússia. Disponível em: <http://www.russobras.com.br/historia/historia_5.php>. Acesso em: 03 de out. 2012.

INDEX MUND. Produto Interno Bruto (PIB) - Taxa de Crescimento Real (\%). 2011. Disponível em: 〈http://www.indexmundi.com/g/g.aspx?v=66\&c=kz\&l=pt>. Acesso em 31 out. 2012.

JORDAAN, Eduard Christiaan. The Concept of a Middle Power in International Relations: Distinguishing between Emerging and Traditional Middle Powers. In: Politikon: South African Journal of Political Studies, Vol 20, $\mathrm{n}^{\mathrm{o}}$ 2, p. 165-181. Disponível em: 〈http://ink.library.smu.edu.sg/soss_research/394/ >. Acesso em 20 fev. 2013.

JORNAL DO BRASIL. Crise na Espanha faz renascer clamor separatista na Catalunha. $\quad 30 \quad$ set. 2012 . $\quad 30$ Disponível $<$ http://www.jb.com.br/internacional/noticias/2012/09/30/crise-na-espanha-faz-renascerclamor-separatista-na-catalunha/> . Acesso em 23 fev. 2013.

JSC "National Agency for Export and Investment - KAZNEX INVEST. Economic policy of Kazakhstan on the modern stage. Invest in Kazakhstan. Disponível em: <http://www.invest.gov.kz/?option=content\&section=1\&itemid=67 >. Acesso em 29 out. 2012.

KEOHANE, Robert; NYE, Joseph S. Power and Interdependece. Longman, 2000. 3Ed. $352 \mathrm{p}$.

MAZZI, Carolina. Recuperação espanhola só acontecerá com fim das medidas de austeridade. Jornal do Brasil. 21 maio 2012. Disponível em: $<$ http://www.jb.com.br/economia/noticias/2012/05/17/recuperacao-espanhola-so-aconteceracom-fim-das-medidas-de-austeridade/>.

KRAMER, Andrew E. Central Asia on Front Line in Energy Battle. The New York Times, 20 dez. 2007.2 Disponível em: <http://www.nytimes.com/2007/12/20/business/worldbusiness/20gas.html?_r=1\&pagewa

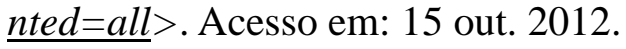

NYE JR., Joseph S. Compreender os Conflitos Internacionais: Uma Introdução à Teoria e à História. Cidade: Gradiva, 2002, 320 p. (Coleção Trajectos).

ROYDS, Mollie. Middlepowerism in the Post-Cold War Era: A Critique of Axworthy's Security Policy. Calgary: University of Calgary, 2000. 18 p. 
Sobre $\quad$ o $\quad$ Cazaquistão. $\quad$ Disponível em: 〈http://www.pacificprime.com/pr/countries/kazakhstan/about/ >. Acesso em: 8 nov. 2012.

STAIRS, Denis. Of Medium Powers and Middling Roles. Dalhousie University, Nova Scotia, 2008. Disponível em: http://politicalscience.dal.ca/Files/syllabi_docs/fall08/poli2520/Lecture18.pdf>. Acesso em: 3 out. 2012.

STENGEL, Bernhard von; TUROCY, Theodore L. Game Theory. CDAM Research Report LSE-CDAM-2001-09, out. 2001. Disponível em: 〈http://www.cdam.lse.ac.uk/Reports/Files/cdam-2001-09.pdf〉. Acesso em: 07 fev. 2013.

THE ECONOMIST. Not-quite-eternal Nursultan: A success story, but the ending is not yet written. The Economist Newspaper Limited, 17 dez. 2011. Disponível em: $<$ http://www.economist.com/node/21541853?zid=309\&ah=80dcf288b8561b012f603b9fd9577f0e >. Acesso em: 10 set. 2012.

USAID: The United States Agency for International Development. Countries. Estados Unidos. Disponível em: 〈http://centralasia.usaid.gov/countries〉. Acesso em 30 out. 2012.

VISENTINI, Paulo Fagundes. As relações diplomáticas da Ásia: articulações regionais e afirmação mundial: (uma perspectiva brasileira). Belo Horizonte: Fino Traço, 2012. 275 p. (Coleção Relações internacionais; 4 Série Parcerias estratégicas com o Brasil).

YERGIN, D., O Petróleo: uma história de ganância, dinheiro e poder, São Paulo: Editora Scritta,1994. 932 p. 